\title{
An Integrated Entropy-TOPSIS Method for Soil Conservation Assessment in Qijiachuan Demonstration Area
}

\author{
Chunxiao Wang ${ }^{1 *}$, Linjing Yan ${ }^{1}$, Xiangming Kong ${ }^{1}$, Jing Zhao ${ }^{1}$, Yongping Li $^{2}$ \\ 1. College of Fundamental Research, Beijing Polytechnic, Beijing 100176, China \\ 2. School of Environment, Beijing Normal University, Beijing 100875, China \\ E-mail: chunxiao20083366@163.com
}

\begin{abstract}
In this study, an entropy theory based technique for order preference by similarity to an ideal solution (Entropy-TOPSIS) method is proposed for assessing soil conservation benefits in Qijiachuan demonstration area of Yellow River basin. Entropy-TOPSIS method integrating entropy theory into TOPSIS model can deal with qualitative and quantitative data during assessment processes. The developed method is then applied to soil conservation assessment in Qijiachuan demonstration area. Soil conserved of different measures in different periods has been calculated. Results indicate that soil conserved in period $3(2028-2037)$ ranks the first due to the high vegetation coverage. Soil conserved of cellar, gully head protection and check dam would decrease from period 1 (2008-2017) to period 3 due to the reduced function after years of silting up. Thus, it is necessary to take good maintenance measures to promote function recovery of gully head control measures.
\end{abstract}

Keywords-Soil conservation; TOPSIS; Entropy; Qijiachuan; Yellow River

\section{INTRODUCTION}

Soil is one of basic factors for survival and must be protected for future generations [1]. In Loess Plateau, the area of soil erosion constitutes $70 \%$ of the total region and thus restricts the development of local rural economy and affects the social sustainable development [2]. In order to investigate the situation of soil erosion and its harmfulness in this region, sediment transport monitoring sites have been built to quantify the amount of soil erosion. At the same time, a wide variety of measures (e.g., stripe lands, gully head control works, reservoirs and afforestation) used to prevent erosion has been established. However, there are relatively few studies in quantify or assessment of their performance in reducing soil erosion [3]. Through integrating entropy theory into technique for order preference by similarity to an ideal solution (TOPSIS), an Entropy-TOPSIS method will be developed to assess the benefits of the existing soil conservation projects in Qijiachuan demonstration area of Yellow River basin. Results would be helpful for identifying effective soil conservation measures and forming satisfactory management mechanisms.

\section{MATERIAL AND METHOD}

\section{A. Study area}

Located in Loess Plateau with a plateau-gully-slope morphological pattern, Qijiachuan is a typical semiarid area in China. The average annual rainfall is $552.1 \mathrm{~mm}$, with a maximum of $802.5 \mathrm{~mm}$ and a minimum of $327.6 \mathrm{~mm}$. Due to the special topography and the low rainfall, this district experiences heavy soil losses, which poses great challenges to sustainable development. Qijiachuan Demonstration Project for Soil and Water Conservation and Ecological Engineering of Yellow River was finished in 2007 for environmental restoration [4]. Soil conversation measures including cellars, check dams, gully head protection, mixed forest and terraced fields were built. However, because of ineffective management (e.g., no irrigation), most of these measures cannot play long-term role in soil conservation. For pursuing the sustainability among society, economy and environment, it is urgent to evaluate function of soil conservation measures to explore effective management mechanism and disclose what measures should be taken to stop erosion.

\section{B. Selection of indicators}

The effect of soil conservation measures is surrounded with a variety of uncertainties deriving from spatial variations related to hydrological and terrain factors (e.g., slope). The indicators should fully consider the soil conservation measures and terrain factors, as well as represent the complexities among them. Methods in GB/T15774-2008 for calculating benefits of soil and water conservation measures has been widely used for indicator selection and proved efficient and rational in assessing soil conservation benefit [5]. Based on the special topography in the study region, three aspects of soil conservation benefit, i.e., the amount of soil conserved from measures in plateau area, gully area and slope area, are considered. Based on expert consultation, field investigation and literature investigation, the assessment indicators of the Qijiachuan demonstration area are presented in Table 1. 
TABLE I INDICATORS FOR SOIL CONSERVATION ASSESSMENT

\begin{tabular}{|c|c|c|}
\hline First layer & Second layer & Third layer \\
\hline \multirow{10}{*}{ Soil conservation } & \multirow{4}{*}{ Soil conserved in plateau area } & Cellar \\
\hline & & Nursery \\
\hline & & Shelterbelt \\
\hline & & Economic forest \\
\hline & \multirow{2}{*}{ Soil conserved in gully area } & Gully head protection \\
\hline & & Check dam \\
\hline & \multirow{4}{*}{ Soil conserved in slope area } & Terraced field \\
\hline & & Grassland \\
\hline & & Shrubbery \\
\hline & & Arbor forest \\
\hline
\end{tabular}

\section{Data collection and analysis}

The data of slope gradient, number of cellars, acreage of forests and the possible damage or loss of soil conservation measures are acquired from experts' knowledges, extensive literatures and local reports from Xifeng Supervision Bureau of Yellow River Conservancy Commission (http://www.hw-xf.com), as well as statistics from the United Nations Development Programme (UNDP). In the demonstration area, plateau area with a slope gradient less than 5 degrees is the main farm products base. Slope area, with a slope gradient between 7 and 25 degrees, is the ramp zone from plateau area to gully area. The slope gradient in gully area is more than 25 degrees, indicating the highest erosion risk in the study area [6-7]. With consideration of slope gradient, the modulus of soil erosion for nursery, shelterbelt, economic forest, terraced field, grassland, shrubbery, and arbor forest can be determined according to the standards for classification and gradation of soil erosion (SL190-2007). The amount of soil conserved can be estimated based on the modulus of soil erosion for different measures (e.g., terraced and grassland).

With consideration of vegetation coverage and designed service life, the 30-year planning horizon (2008-2037) is divided into three time periods, with each having an interval of 10 years. The annual soil amount conserved from conservation measures can be determined based on unit amount of soil conserved and their corresponding acreages or total numbers. In different period, the amount of soil conserved would be different due to different type and growth of the forests. Thus, the unit amounts of soil conserved from different measures in different periods, i.e., 2008-2017 is period 1 (P1), 2018-2027 is period $2(\mathrm{P} 2)$ and $2028-2037$ is period $3(\mathrm{P} 3)$, are shown in Table 2.

TABLE II UNIT AMOUNT OF SOIL CONSERVED

\begin{tabular}{|c|c|c|c|c|c|c|c|c|c|}
\hline \multirow{2}{*}{$\begin{array}{l}\text { Soil conservation } \\
\text { measures }\end{array}$} & \multicolumn{3}{|c|}{$\begin{array}{l}\text { Unit amount of soil } \\
\text { conserved }(\mathrm{t} / \mathrm{ha} \cdot \mathrm{a})\end{array}$} & \multirow{2}{*}{$\begin{array}{l}\text { Total area } \\
\text { (ha) }\end{array}$} & \multirow{2}{*}{$\begin{array}{l}\text { Soil conservation } \\
\text { measures }\end{array}$} & \multicolumn{3}{|c|}{$\begin{array}{l}\text { Unit amount of soil } \\
\text { conserved (t/a) }\end{array}$} & \multirow{2}{*}{$\begin{array}{l}\text { Total } \\
\text { number }\end{array}$} \\
\hline & P1 & $\mathrm{P} 2$ & P3 & & & $\mathrm{P} 1$ & $\mathrm{P} 2$ & P3 & \\
\hline Nursery & 20 & 36 & 36 & 5.1 & Cellar & 10 & 8 & 6 & 93 \\
\hline Shelterbelt & 10 & 16 & 28 & 53.5 & $\begin{array}{ll}\text { Gully } & \text { head } \\
\text { protection } & \end{array}$ & 30 & 26 & 20 & 55 \\
\hline Economic forest & 12 & 18 & 30 & 391.8 & Check dam & 8 & 6 & 4 & 1029 \\
\hline Terraced field & 18 & 36 & 36 & 1075.6 & & & & & \\
\hline Grassland & 18 & 32 & 32 & 761.2 & & & & & \\
\hline Shrubbery & 12 & 19 & 30 & 391.8 & & & & & \\
\hline Arbor forest & 10 & 15 & 25 & 1902.0 & & & & & \\
\hline
\end{tabular}

D. Assessment process

It is an important step to choose proper indicators' weights for TOPSIS [8]. Based on the objective information of indicators, indicators' weights can be calculated objectively by using entropy theory, eliminating the influence brought by subjective estimation. In detail, the weight for each indicator can be calculated as follows: 


$$
\begin{gathered}
P_{i j}=x_{i j} / \sum_{i=1}^{m} x_{i j} \\
E E_{j}=-\frac{1}{\operatorname{Ln} m} \sum_{i=1}^{m}\left[P_{i j} \times \operatorname{Ln} P_{i j}\right] \\
W_{j}=\left(1-E E_{j}\right) / \sum_{j=1}^{n}\left(1-E E_{j}\right)
\end{gathered}
$$

where $x_{i j}$ and $E E_{j}$ are the amount of soil conserved and the entropy value of $j$ th the jth soil conversation measure. $w_{j}$ is the weight of the $j$ th indicator.

TOPSIS is one of the multi-criteria decision analysis method usually utilized in system engineering to analyze the objective decision [9]. It ranks using the relative proximity calculated based on the distance from the positive/negative ideal solution. To rank the benefits of different soil conservation measure under different conditions, the distance from the positive and negative ideal solution should be calculated. In detail, the weighted standardized matrix should be formulated first [10]. Then the positive and negative ideal solution can be calculated as follows:

$$
\begin{gathered}
v_{k}^{+}=\left(\max v_{l k}\left|k \in k^{+}\right|, \min v_{l k}\left|k \in k^{-}\right|\right) \quad l=1, \ldots, m \\
v_{k}^{-}=\left(\min v_{l k}\left|k \in k^{+}\right|, \max v_{l k}\left|k \in k^{-}\right|\right) \quad l=1, \ldots, m
\end{gathered}
$$

where $v_{k}^{+}$is the positive ideal solution, and $v_{k}^{-}$is the negative ideal solution. The distance from the positive/negative ideal solution can be calculated to determine the relative proximity of soil conservation benefit to the ideal solution as follows:

$$
S S_{l}^{+}=\sqrt{\sum_{k=1}^{n}\left(v_{l k}-v_{k}^{+}\right)^{2}} \quad l=1, \ldots, m
$$

$$
S S_{l}^{-}=\sqrt{\sum_{k=1}^{n}\left(v_{l k}-v_{k}^{-}\right)^{2}} \quad l=1, \ldots, m
$$

$$
C_{l}=\frac{S S_{l}^{-}}{S S_{l}^{+}+S S_{l}^{-}} \quad l=1, \ldots, m
$$

where $S S_{l}^{+}$and $S S_{l}^{-}$are the distance from the positive and negative ideal solution, respectively. $C_{l}$ is the relative proximity to the ideal solution. A larger $C_{l}$ value indicates a higher soil conversation benefit.

\section{RESULT AND DISCUSSION}

According to the entropy theory and TOPSIS, the entropy values and weights of different indicators, as well as their positive and negative ideal solutions are shown in Table 3. Low entropy values relate to high weights, indicating high influential of indictors. Results reveal that gully head protection and shelterbelt are the most important indicators and their weights are $15.44 \%$ and 15.28 , respectively. The weights of soil conservation in plateau area, gully area and slope area are respectively $40.14 \%, 22.20 \%$ and 37.66 . The distances from the positive/negative solution are $0.1354 / 0.0894$ for $\mathrm{P} 1$, $0.0842 / 0.0833$ for P2 and $0.3834 / 0.4823$ for $\mathrm{P} 3$, which are used to determine the relative proximity to the ideal solution. Results indicate that soil conserved in P3 ranks the first with the value of 0.6166 followed by P2 (i.e. 0.1354); P1 owns the lowest value (i.e. 0.38), which can be attributed to the low vegetation coverage degree in this period.

TABLE III WEIGHTS OF INDICTORS, THE POSITIVE AND NEGATIVE IDEAL SOLUTIONS

\begin{tabular}{lllll}
\hline Soil conservation measures & Entropy & Weights & $\mathrm{v}^{+}$ & $\mathrm{v}-$ \\
\hline Cellar & 0.9660 & 0.0669 & 0.0487 & 0.0243 \\
Nursery & 0.9704 & 0.0583 & 0.0384 & 0.0213 \\
Shelterbelt & 0.9223 & 0.1528 & 0.1267 & 0.0453 \\
Economic forest & 0.9372 & 0.1234 & 0.1001 & 0.0400 \\
Gully head protection & 0.9215 & 0.1544 & 0.1149 & 0.0383 \\
Check dam & 0.9656 & 0.0676 & 0.0502 & 0.0251 \\
Terraced field & 0.9602 & 0.0782 & 0.0521 & 0.0261 \\
Grassland & 0.9715 & 0.0561 & 0.0369 & 0.0207 \\
Shrubbery & 0.9395 & 0.1189 & 0.0952 & 0.0381 \\
Arbor forest & 0.9372 & 0.1234 & 0.1001 & 0.0400
\end{tabular}

To show the relationship of soil conserved between different measures, Figure 1 depicts the amount of soil conserved of different measures in different periods. From P1 to P2, soil conserved of shelterbelt, economic forest, shrubbery 
and arbor forest would increase due to the increase of vegetation coverage degree as they grow. Soil conserved of cellar, gully head protection and check dam would decrease, because of the reduced function after years of silting up. From the perspective of sustainable use of measures, shelterbelt, economic forest, shrubbery and arbor forest have advantage over cellar, gully head protection and check dam in long term soil conservation. Thus, it is necessary for good maintenance measures (e.g., irrigation and fertilization) to ensure survival, as well as healthy tree growth and development to achieve the effect of soil conservation.

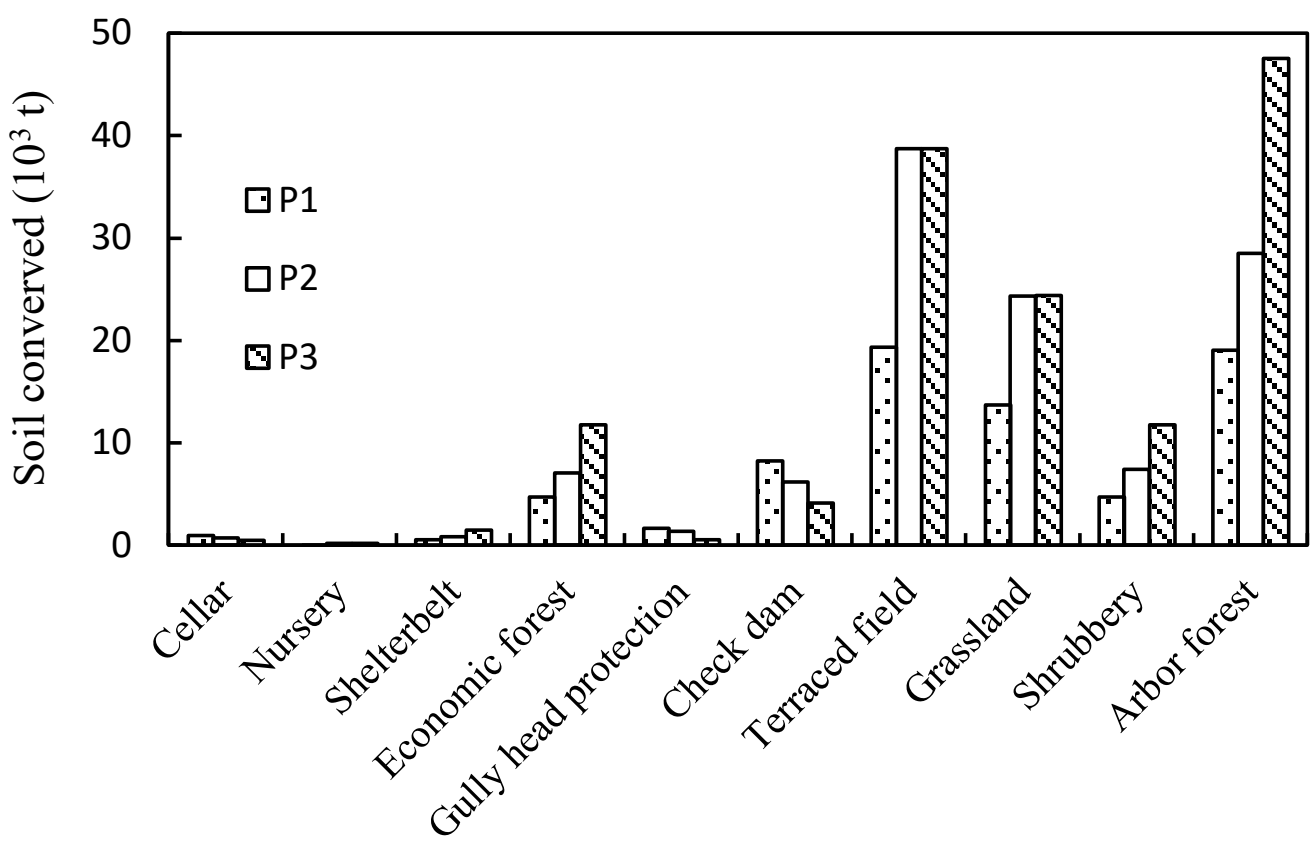

Fig. 1 Soil conserved of different measures in different periods

The total amount of soil conserved is $329.32 \times 103 \mathrm{t}$, with $72.93 \times 103 \mathrm{t}$ in $\mathrm{P} 1,115.43 \times 103 \mathrm{t}$ in $\mathrm{P} 2$ and $140.95 \times 103 \mathrm{t}$ in $\mathrm{P} 3$. It is indicated that soil conservation would increase from $\mathrm{P} 1$ to $\mathrm{P} 3$. This is because that the increase of soil conservation associated with the vegetation coverage degree increase is more than the decrease associated with reduced function. Soil conserved in plateau area, gully area and slope area are $9 \%$, $13 \%, 78 \%(\mathrm{P} 1), 8 \%, 6 \%, 86 \%(\mathrm{P} 2)$ and $10 \%, 3 \%$ and $87 \%(\mathrm{P} 3)$ of the total value. Soil conserved in slope area has the largest portion, which can be attributed to the popularization of afforestation in such terrain. In comparison, because of the deficiency of investment fund, soil conserved in gully area decreases from P1 to P3 and has the smallest proportion in P2 and P3. Much more money should be invested to promote function recovery of gully head control measures.

\section{CONCLUSIONS}

This study has developed an integrated Entropy-TOPSIS method to support soil conservation in Qijiachuan demonstration area of Yellow River basin. Through incorporating entropy theory and TOPSIS into a general framework, Entropy-TOPSIS method is not only capable of using both qualitative and quantitative data during the assessment processes, but also helpful for deciding indicators' weights with elimination of the influence brought by subjective estimation. The method is then applied to assess soil conservation benefit in Qijiachuan demonstration area and the amounts of soil conserved of different measures in different periods are calculated. Results indicate that soil conserved in P3 ranks the first due to the high vegetation coverage degree. Soil conserved of cellar, gully head protection and check dam would decrease from $\mathrm{P} 1$ to $\mathrm{P} 3$ due to the reduced function after years of silting up. Thus, it is necessary to invest more money to achieve environmental benefits. Moreover, in terms of long term interests, shelterbelt, economic forest, shrubbery and arbor forest have advantage over cellar, gully head protection and check dam in long term soil conservation and should be widely planted.

\section{ACKNOWLEDGEMENT}

This research was supported by the major research program of Beijing Polytechnic, Beijing (2018Z002-004-KXB). 


\section{REFERENCES}

[1] Graaff J D, Aklilu A, Ouessar M, et al. The development of soil and water conservation policies and practices in five selected countries from 1960 to 2010 [J]. Land Use Policy, 2013, 32(3):165-174.

[2] Pan X J. Design Peak Flow Analysis and Calculation Qijiachuan River Pingan County $[\mathrm{J}]$. Science \& Technology of Qinghai Agriculture \& Forestry, 2013.

[3] Lin J, Zhu G, Wei J, et al. Mulching effects on erosion from steep slopes and sediment particle size distributions of gully colluvial deposits[J]. Catena, 2018, 160:57-67.

[4] Liang S, Zeng X T, Yong-Pin L I, et al. The Effect Evaluation of Operation and Management on Soil and Water Conservation Project Based on Entropy Fuzzy Credibility-constrained DEA Method[J]. China Rural Water \& Hydropower, 2015.

[5] Pan X J. Design Peak Flow Analysis and Calculation Qijiachuan River Pingan County[J]. Science \& Technology of Qinghai Agriculture \& Forestry, 2013.

[6] Zhang X W. Soil erosion risk and its spatial pattern in upstream area of Guanting reservoir[J]. Environmental Earth Sciences, 2012, 65(1):221-229.

[7] Chen D, Wei W. Effects of terracing on soil and water conservation in China: A meta-analysis[C]// EGU General Assembly Conference. EGU General Assembly Conference Abstracts, 2017.

[8] Lei X, Robin Q, Liu Y. Evaluation of regional land use performance based on entropy TOPSIS model and diagnosis of its obstacle factors[J]. Transactions of the Chinese Society of Agricultural Engineering, 2016.

[9] Hsu P F, Hsu M G. Optimizing the Information Outsourcing Practices of Primary Care Medical Organizations Using Entropy and TOPSIS[J]. Quality \& Quantity, 2008, 42(2):181-201.

[10] Liang X, Liu C, Li Z. Measurement of Scenic Spots Sustainable Capacity Based on PCA-Entropy TOPSIS: A Case Study from 30 Provinces, China [J]. International Journal of Environmental Research \& Public Health, 2018, 15(1):10. 